\title{
Upwelling Solution Prototype Using Wireless Sensor Network
}

\author{
Novian Anggis Suwastika ${ }^{\# 1}$, Sidik Prabowo ${ }^{* 2}$, Bayu Erfianto ${ }^{\# 3}$, Aji Gautama P. ${ }^{\# 4}$ \\ \# School of Computing, Telkom University \\ Telekomunikasi Street $1^{\text {st }}$, Bandung, West Java, Indonesia \\ 1 anggis@telkomuniversity.ac.id \\ 2 pakwowo@telkomuniversity.ac.id \\ 3erfianto@ telkomuniversity.ac.id \\ a ajigps@telkomuniversity.ac.id
}

\begin{abstract}
One of the problem in the freshwater fisheries sector is that the phenomenon of upwelling can occur anytime without warning signs, especially in lakes. This problem causes a failed harvest and fish farming business owners suffer a great loss due to the death of fish in large numbers. Upwelling caused by toxic substances results in increased nitrification from fish feces and remaining fish feed deposited at the bottom of the Lake rise to the surface quickly. Ammonia (NH3) that are in ionized form cause no fish around the surface of the Lake because of the lack of oxygen to meet the needs of hemoglobin, so oxygen cannot be bind or lack of dissolved oxygen (DO). This condition causes the death of a lot of fish. This research builds a monitoring system to monitor the condition of the temperature at the surface and at the underwater (5-20 m from the surface) of the lake and to monitor DO levels to check the possibility of upwelling. Temperature sensors and a DO sensor is connected with a microcontroller and GSM networks which are connected to the internet, which helps the fish farmer and related parties to monitor continuously the conditions of farmed fish. The results obtained by system experiment on the fish farms area (karamba) and non-fish farms area, are accurate and real time.
\end{abstract}

Keywords: microcontrollers, upwelling, monitoring system, multi-sensor, dissolved oxygen, temperature, wireless sensor network, machine to machine communication, freshwater

\section{INTRODUCTION}

$\mathbf{U}$ pwelling is the phenomenon of the rise of the cold-temperature water and its sediments from the bottom of the waters towards the surface waters vertically that can occur in salt water (the sea) and freshwater (Lakes) (Shaw, P.T., et al, 1996). On salt water (sea) which has a dynamic flow of water tendency, this phenomenon is lifted from the bottom towards the aquatic nutrients surface waters. While in fresh water, where water flow current tends to be static, this phenomenon causes the rise of toxic material i.e. fish feed and fish droppings left containing ammonia (NH3) from the base to the surface of the water. In fresh water, at the time of the rise of oxygen reduction occurred because the material is pushed by toxic gasses (NH3) thus causing a number of dissolved oxygen levels dropped dramatically. A certain boundary on these conditions very dangerous to fish because it can cause fish death from lack of DO. Some large number dead fish cases due to the upwelling cause huge losses, for example in 2009 in Cirata lake upwelling caused 50 tons of dead fish, in the same year at Lake Maninjau, West Sumatra as much 13,000 tons of dead fish, and the last case in 2015 fish farmers in Lake Jatibarang, suffered losses of up to 400-million-rupiah due to the death of fish caused by upwelling.

The influential parameters to determine the potential occurrence of upwelling is the temperature difference between the temperature below the surface and temperature on the surface of the water and DO levels in the 
Novian A SuWastika Et.al.

water. Checking the parameters of temperature and DO manually and periodic is difficult to do. It needs a system that is able to extract the data of temperature and DO on an ongoing basis. Based on wireless sensor network (WSN) and machine to machine (M2M) communication and wireless sensor network, we built the system to monitor the below and surface temperature of the water and DO level using sensors connected to the microcontroller. The microcontroller is connected to the internet, so that each sensor sensing will be sent to the server. The data acquired and stored on the server will be sent to the end user device. The monitoring system was tested in an experiment environment to ensure the device goes according to design. The system that has been tested on experimental environments are then tested in the real environment

\section{LITERATURE REVIEW}

Freshwater upwelling generally occurs in the rainy season with low sunlight conditions and cold winds causing the temperature on the surface of the water to become colder (Shaw, P.T., et al, 1996) (Quibell, G., 1992). Temperature in the cold surface causes the density of water at the surface to become more severe. If the density of water at the surface is heavier than the density of water at the bottom, upwelling would happen because the water on the surface of the water will shift the bottom waters. In the process of rising water from the bottom to the surface, the material in the bottom water will go up. Material on the bottom of the water is formed from sinking fish feed and fish feces. In freshwater material in the bottom waters tend to be toxic because it contains NH3, H2S and NO2 (tseng2014). Symptoms of freshwater upwelling are indicated from physical parameters, biological parameters, and chemical parameters. Physical parameters are shown on the change of water that become clearer due to the mass death of plankton and the temperatures differences in surface to bottom water are significant and drastic. Biological parameters are shown on the phenomenon of plankton at the surface of the water, for examples flagella plankton (Gymnodinium, Paramaecium, etc.). Chemical parameter indications are the DO decline drastically to $1-2 \mathrm{mg} / \mathrm{L}$ and increased levels of NH3, H2S and NO2. The reduction of DO causes aquatic biota having difficulty to breath. These conditions coupled with increased levels of NH3 drastically. At a certain conditions, fish and other aquatic biota can die suddenly.

Upwelling monitoring system has been developed by researchers. Upwelling monitoring system using satellite have been developed by Weeks et al. The study conducted monitoring in the upwelling indicated salted water (sea) in the area of Benguela (Weeks, S. J., et al., 2004). Satellites take algae growth pattern pictures from ocean waters. Algae is a plant which utilizes ammonia to grow. By observing the pattern of growth of algae territories indicating upwelling occurrence possibilities can be specified. In another study conducted by Bakker et al (Bakker, D. C., et al, 2001) observation are taken at post upwelling events by considering some components such as changes and variability of sea level on the terms of $\mathrm{CO} 2$, temperature and fluorescence levels. After a great upwelling events in the Atlantic Ocean in 1997 it was found that there was a significant change in temperature and levels of fluorescence.

Both previous researches is an example of a study conducted in salted water (sea), whereas in the case of freshwater very few research has been done, considering the impact that occurs in fresh water can get worse depending on the pattern of the fish farm. Based on research conducted by Puebla (Puebla, O., 2009), fish in freshwater and seawater has a different character. At freshwater, fish tend to be more able to adapt to environmental changes compared with the fish in the waters of the sea water. However, based on research Tseng et al (Tseng, YF, et al, 2014) in fresh water because flow of water tends to be static, toxic substances from fish feces, residual fish food, and fish carcasses will accumulate and will go up to the surface when upwelling occurs and the substance is toxic to fish. While in the ocean waters toxic substances tend to decompose or spread following the ocean currents.

The use of satellite technology for monitoring upwelling is still not implemented in Indonesia because implementation and operational costs are very expensive. Besides the characters of fresh water and sea water is quite different, especially related to the growth of algae which is the object of observation satellites. The most relevant technology is using sensor and WSN. WSN technology is already widely implemented in various fields. For example, in the areas of health, WSN is used as a monitoring tool such as health research conducted by (Milenković, A., et al, 2006), on the study WSN is applied to monitoring the health of people by medical doctors. The example in the field of smart home research (El-Basioni, B. M. M., et al, 2013) integrates biometric 
with control devices in a house. WSN can also be applied to the detection of forest fires as research conducted by (Yu, L. et al, 2005, September).

Detection and monitoring systems for upwelling based on WSN technology has been carried out by Bondarenko et al (Bondarenko, O., et al, 2007, October). In the study, the authors implement WSN to collect temperature data in the form of 3-D (temperature sensor array). Implementation of this research is the area of the northwest of the Great Barrier Australia (GBR). In another study, Bondarenko et al, (Bondarenko, O., et al, 2007, December) utilizes the data from previous studies to observe and gather plankton correlated with patterns to detect and monitor the presence of upwelling in the area of implementation. Pompili et al (Pompili, D., et al, 2006, September) utilizes acoustic sensors that are integrated with WSN to find the ideal value of the number of sensors needed to obtain optimum sensing results to detect upwelling.

From the literature review, most WSN implementations for detection or monitoring are carried out at sea. In this research a system is developed to monitor water temperature conditions (surface and bottom waters) as well as DO levels, where both parameters are key parameters to detect the possibility of upwelling in freshwater. The system consists of an end node (temperature sensor and DO sensor), gateway / server node (Microcontroller), HSDPA / GSM modem as a connector to the Internet, and devices for end-user interface applications (smartphones, desktop).

\section{A. $D O$}

DO is the dissolved oxygen concentration in water, it is the necessary oxygen to support aquatic organisms. Water DO originate from the diffusion from the atmosphere and from the results aquatic plant photosynthesis such as algae, seaweed, and other aquatic plants. The number of dropouts depend on temperature, pressure, and salinity (Wetzel, R. G., 2001). When the water temperature change becomes higher, the DO levels will fall as shown in Figure 1. DO levels will also drop if the salinity increases so DO levels in fresh water will be $20 \%$ higher when compared with sea water at the same temperature and the same pressure (Langland, M., \& Cronin, T., 2003). On the surface of the water, DO levels can reach $100 \%$ or the same as the DO levels in the air. Getting to the bottom of the water, DO levels in the water decrease due to the respiration of aquatic organisms and microbial decomposition (Fondriest Environmental, inc., 2014).

Other conditions that affect DO levels are respiration and photosynthesis of aquatic plants (Fink, J. C. (2005, August)). In one day, the highest DO level is near sunset because during the day photosynthesis occur, while the lowest levels of DO is before sunrise as shown in Figure 2. The waters with DO levels less than the standard, can lead to the disturbed growth of aquatic organisms. In upwelling conditions, DO levels go down to 1-2 mg/L (Send, U., et al., 2012).

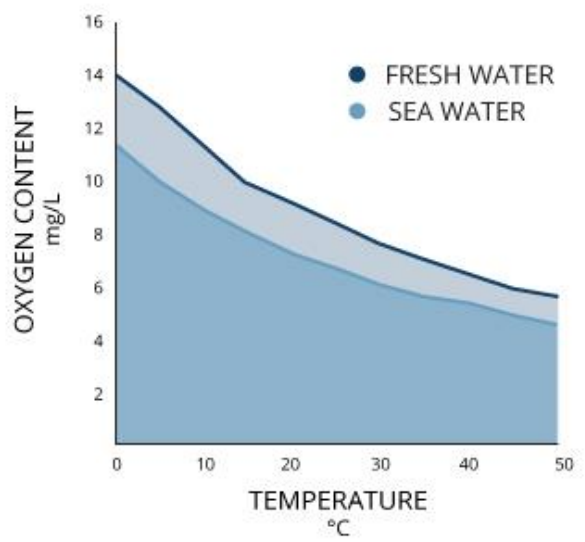

Fig. 1. Correlation between the levels of dissolved oxygen with temperature in the sea water and fresh water (Fondriest Environmental, inc., 2014) 
Novian A Suwastika et.al.

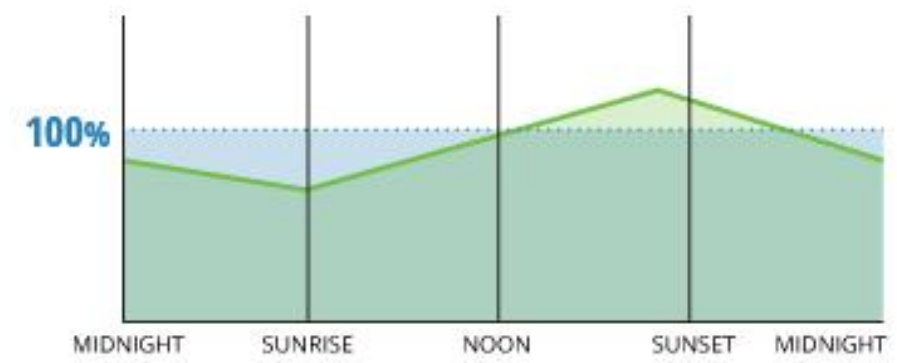

Fig. 2. Photosynthesis impact to the levels of DO in 24 hours (Fondriest Environmental, inc., 2014)

\section{B. Water Temperature}

Temperature is one of the important factors to assess water quality. The water temperature may be used as consideration when we determine the water quality parameters such as metabolic rates and photosynthesis production, compound toxicity, dissolved oxygen and other dissolved gas concentrations, conductivity and salinity, oxidation reduction potential (ORP), pH, and water density (Gao, Q. (2006, November)). Factors that affect the temperature of the water is the sunshine, atmospheric conditions, turbidity, confluence, and manmade Influences. For freshwater areas in Indonesia, the average temperature is between $27^{\circ} \mathrm{C}-30^{\circ} \mathrm{C}$ (Umar, C., 2010).

\section{SYSTEM DESIGN}

\section{A. General Overview of the upwelling monitoring system}

In general design of the system is described in the block diagram in Figure 3. The process that occurs in the monitoring system is reading, updating, and graphics display. The reading process performed by the sensor and sent to the microcontroller. Updates of data occurs on the server / gateway. Graph display can be accessed by end users through the Internet. 


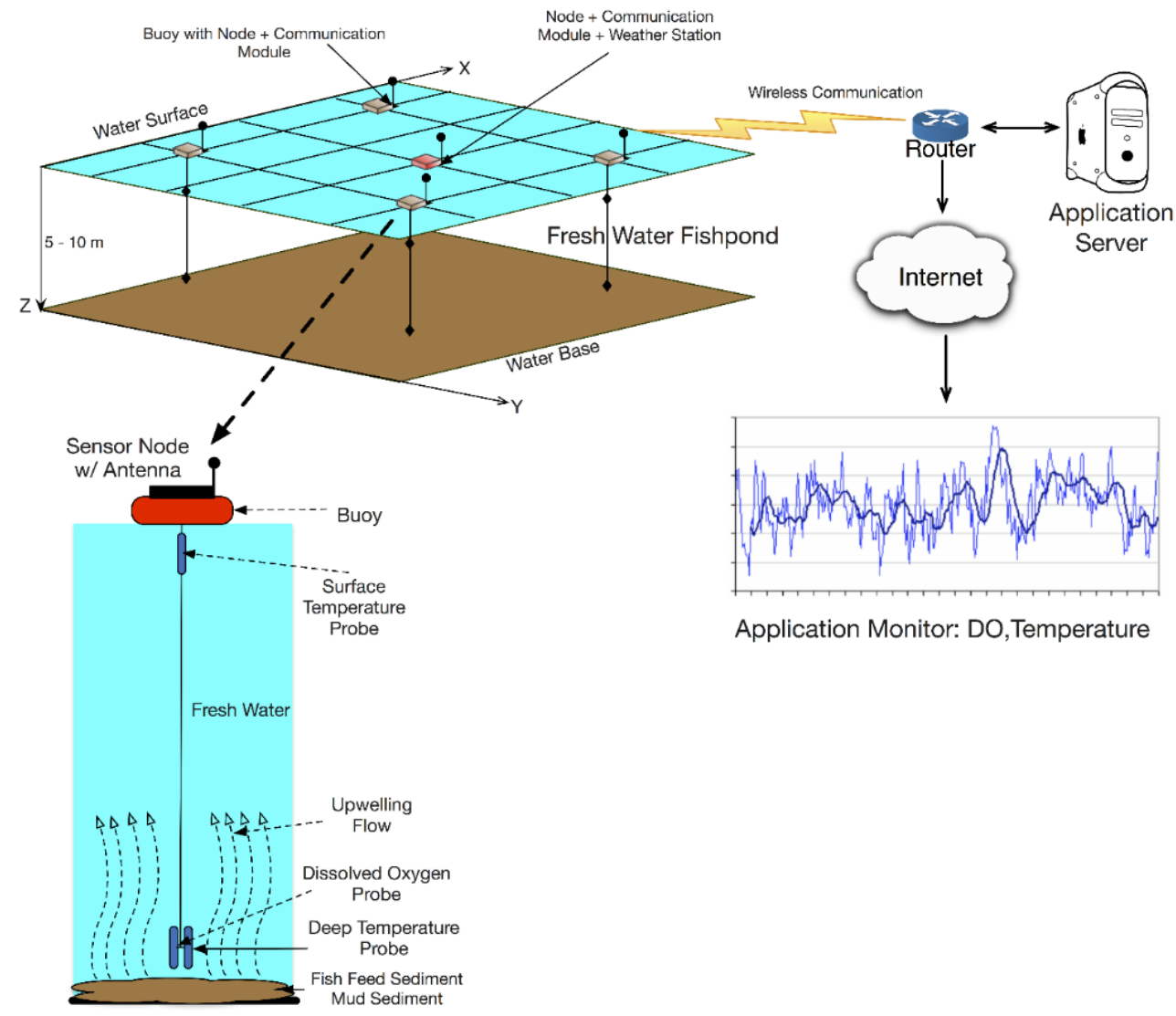

Fig. 3. Upwelling system Model

The monitoring system consists three main components: end nodes, gateway / server, and end-user applications. At the end, nodes place three sensors, which consists of a DO sensor and two temperature sensors. The temperature sensor is placed in two places, namely surface water and bottom waters (sensor cable length is 10 meters). DO sensor is placed at the same depth with temperature sensor. The sensors are connected to a microcontroller that is placed on the buoy as shown in Figure 4. For the needs of electric power, the microcontroller is powered by batteries and solar panels. The data read by the sensor will be stored on the microcontroller and then sent to the gateway / server through the Internet. For internet connection, the microcontroller is connected with HSDPA modem / GSM. Data will be sent to the server every 30 seconds. Data is received by the server / gateway and can be accessed by end users through the user's device. 
Novian A Sumastika et.al.
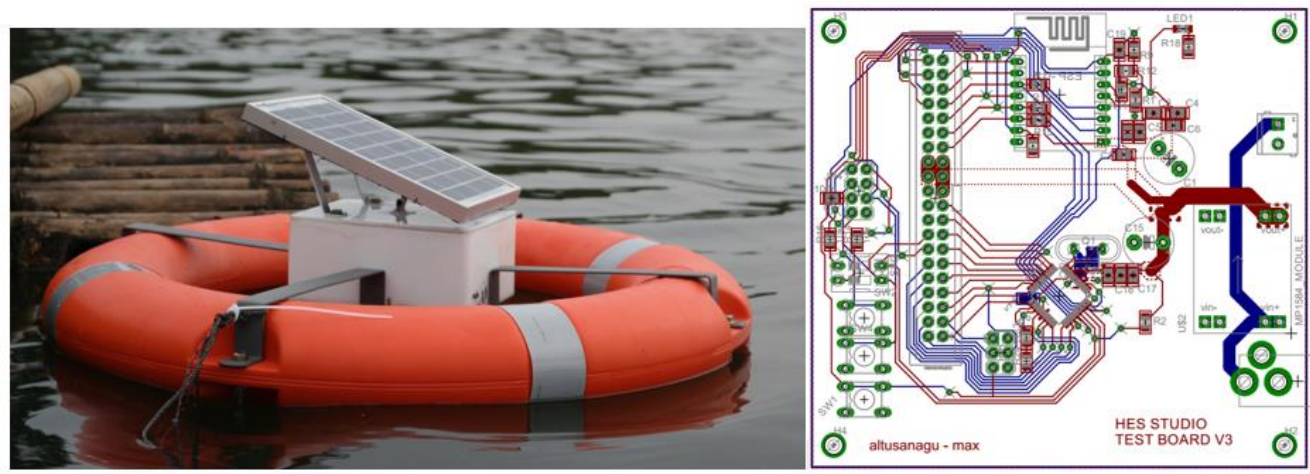

Fig. 4. Upwelling monitoring prototype

\section{B. Testing and Experiment}

To test the functionality of the monitoring system, the device was tested in a test environment. The test environment uses a fiber tub filled with water and placed in the open for 8 days for growing aquatic biota. For validation requirements, we conduct three test scenarios:

a. Experiments on simulated ponds without adding fish and mud

b. Experiments on simulated ponds by adding fish and mud

c. Experiments on simulated ponds by adding fish and mud then stirring the water to check drastically changed DO levels.

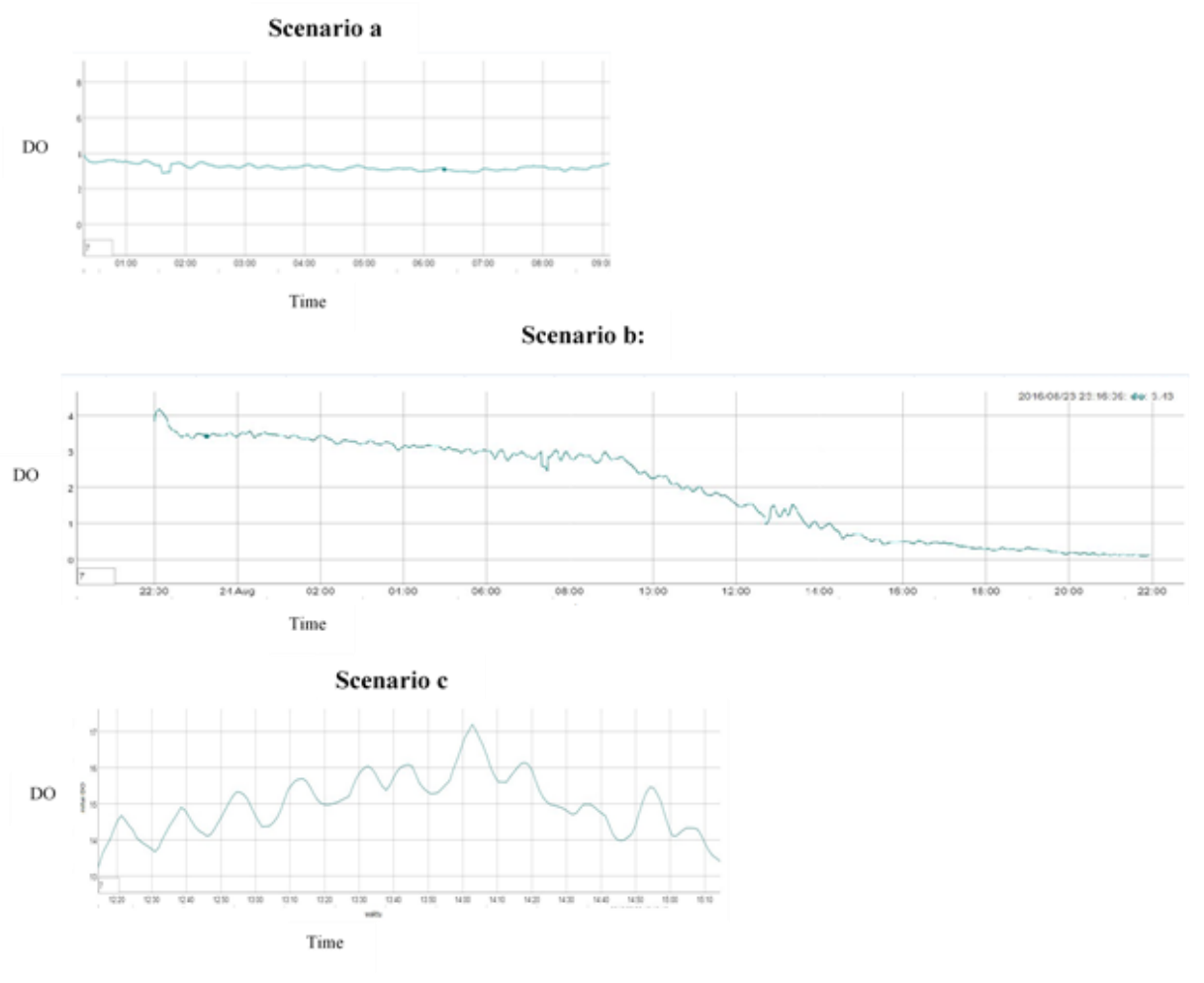

Fig. 5. DO experiment result using three scenarios 
The results of the reading levels of DO and water temperature on outdoor simulations are shown in Figure 5. Of testing against three scenarios, results obtained in scenario (a) are the reading levels of DO and temperature tend to be stable. The necessary DO levels and temperatures changes began to occur in scenario (b). When the simulation scenario (c) is done, the system shows it's capability to read drastic DO and temperature change.

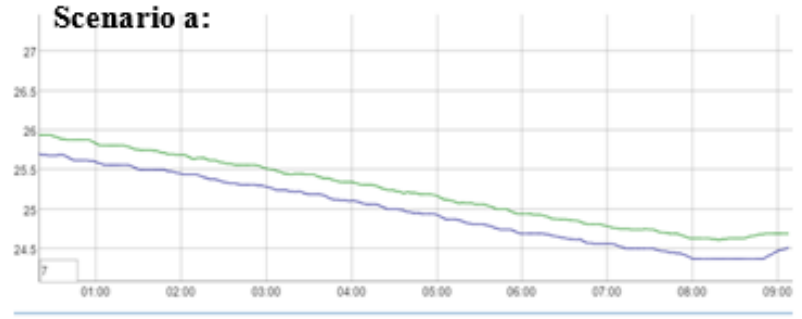

\section{Scenario b:}
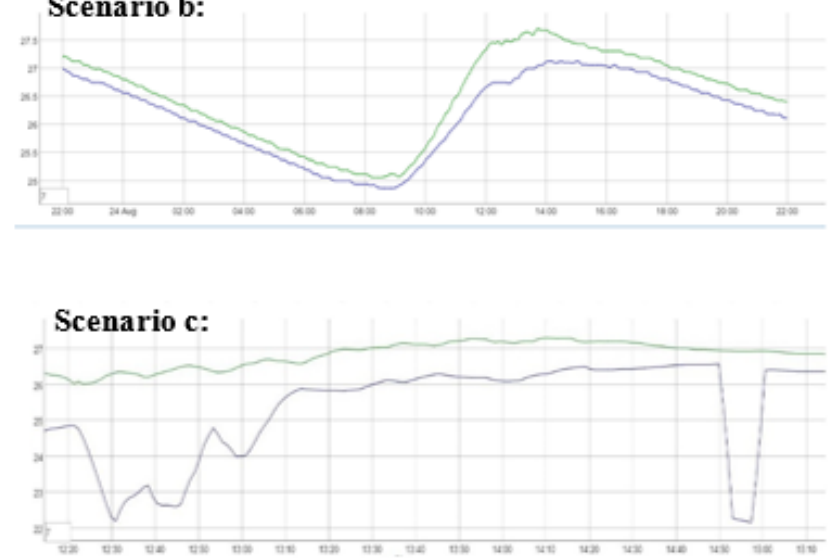

Surface

temperature

\section{Underwater}

temperature

Fig. 6. Temperature experiment result using three scenarios

\section{RESULTS AND DISCUSSION}

The presentation of results should be simple and straightforward. This section reports the most important findings, including results of statistical analysis as appropriate and comparisons to other research results. Results given in figures should not be repeated in tables. This is where Authors should explain in words what he/she/they discovered in the research. It should be clearly laid out and in a logical sequence. This section should be supported suitable references.

After testing on an experimental simulation, device monitoring system was tested on Cirata lake $\left(6^{\circ} 42^{\prime} 2\right.$ "S $\left.107^{\circ} 22^{\prime} 5^{\prime \prime} \mathrm{E}\right)$. Cirata lake is a man-made lake intended as hydroelectricity. Aside from being a hydroelectric plant, most of the lake area is also used as fish farming (karamba). The other half is used as tourist destination. Areas for tourism are left open with no karamba.

Monitoring system testing are performed on two areas. The test is performed to measure the effect of the placement of the karamba on water temperature and DO waters. The measurement results are shown in Figure 7, Figure 8, and Figure 9.

Figure 7 shows that the placement of the karamba, the surface temperature and the bottom waters of karamba area is higher than non karamba area. The average temperature of the surface waters with karamba is $0.88^{\circ} \mathrm{C}$ 
Novian A Suwastika Et.al.

higher than the average temperature of the surface waters without karamba. Figure 8 shows that the temperature of the bottom water with karamba is higher $0.22^{\circ} \mathrm{C}$ compared to the temperature of the bottom waters without karamba. This temperature difference is influenced by aquatic biota such as fish and aquatic plants that are denser in the karamba.

Figure 9 shows the DO levels in areas with karamba are lower than the DO levels in the area without karamba. The average difference in DO levels in both areas is $1: 58 \mathrm{mg} / \mathrm{L}$.

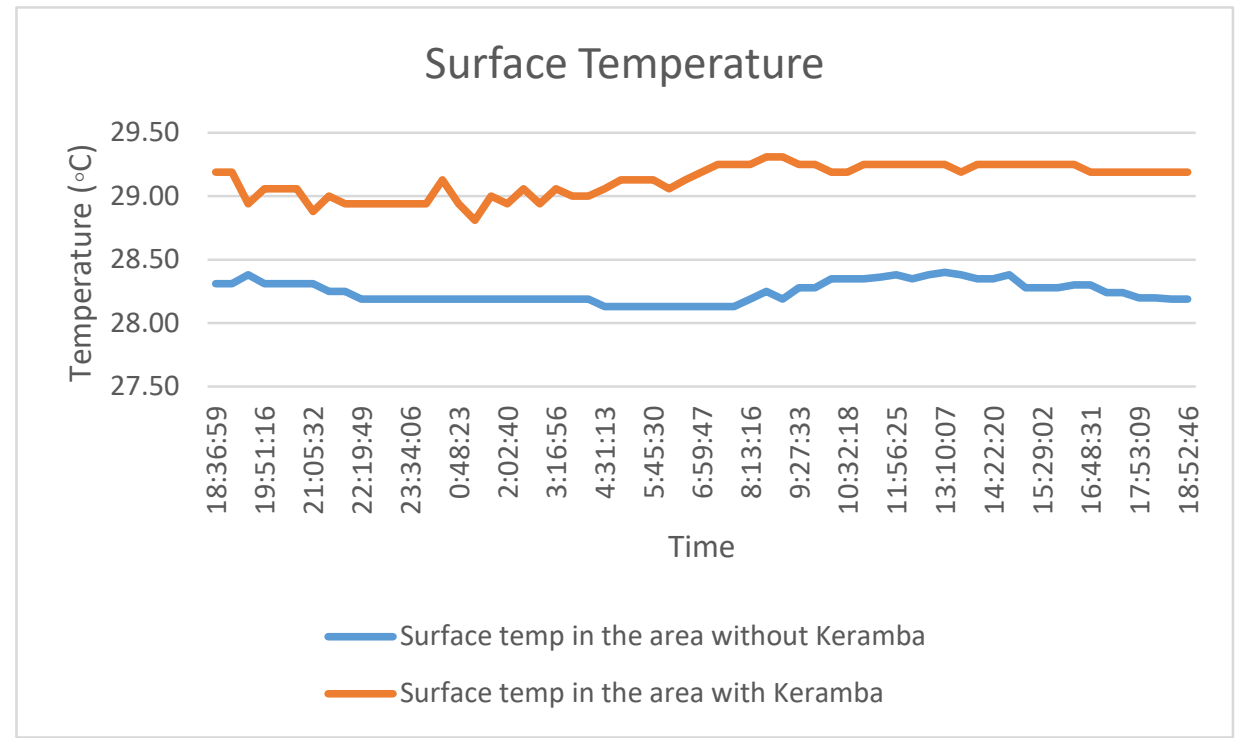

Fig. 7. Surface Temperature

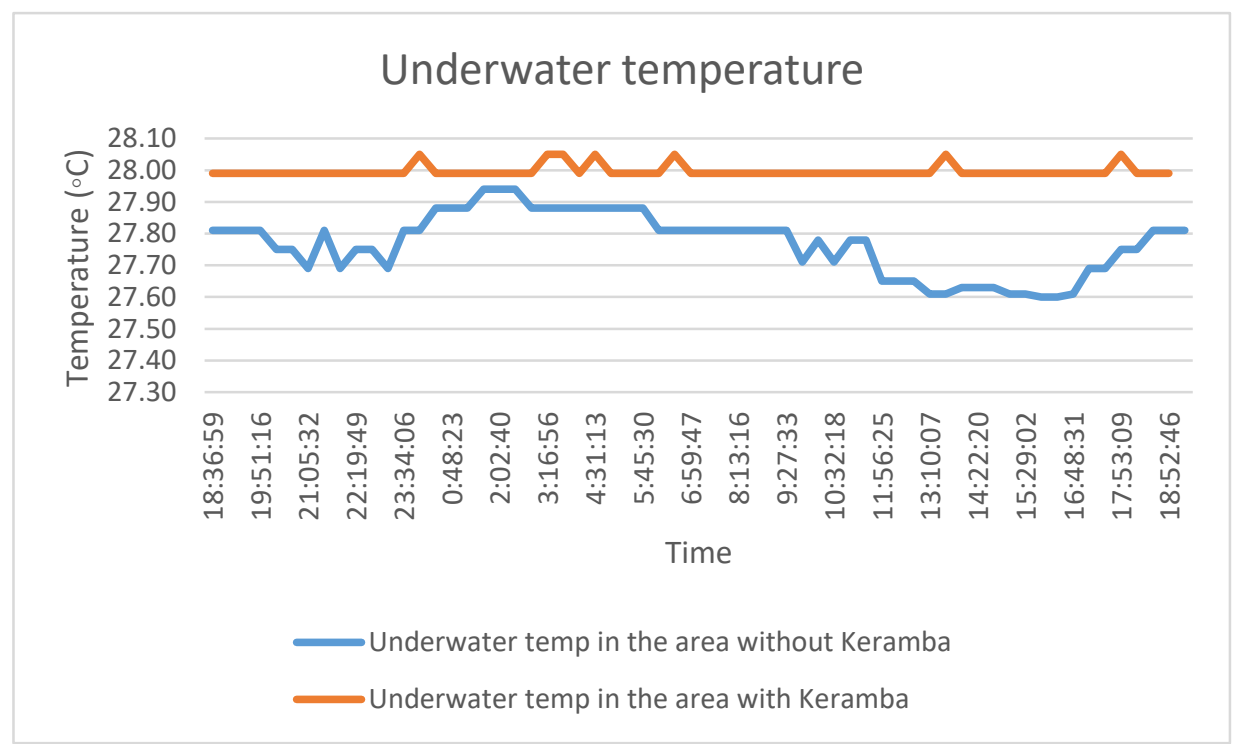

Fig. 8. Underwater temperature 


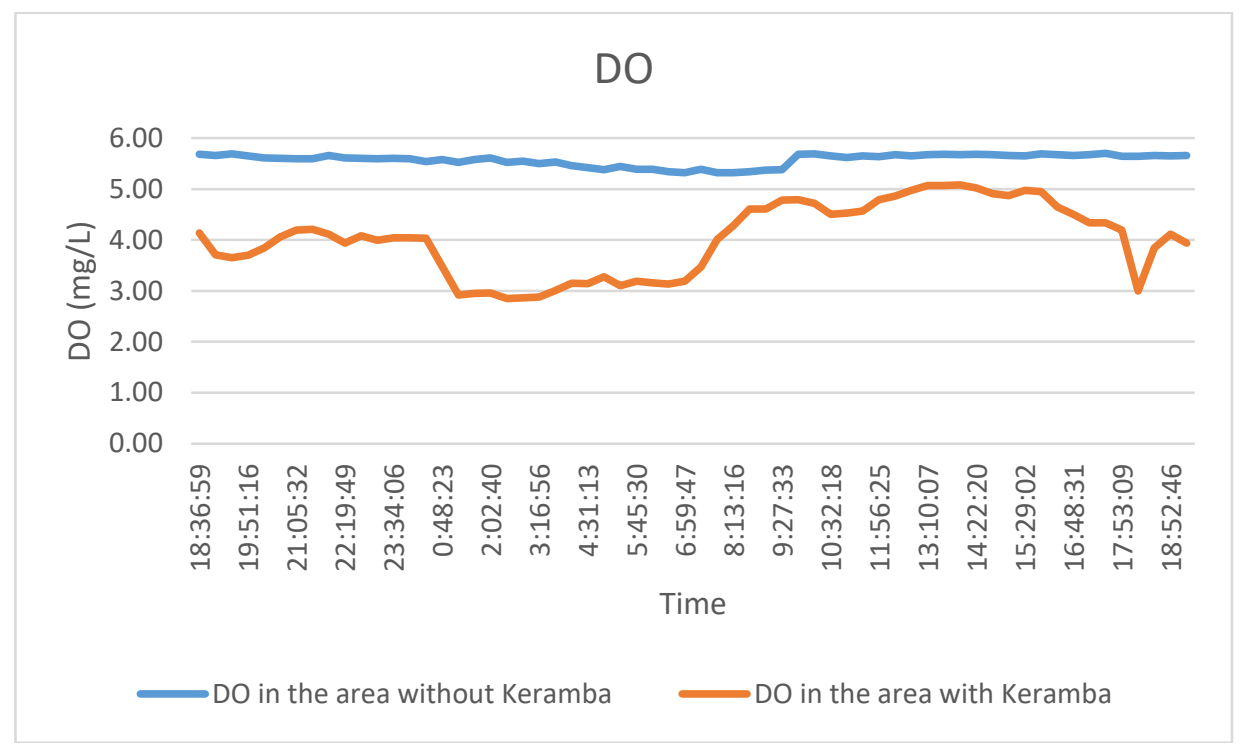

Fig. 9. Dissolve Oxygen captured by System

Based on the test data that has been done, the area has an upwelling occurrence chance, due to several factors, namely: higher water temperatures. When the weather changes suddenly, and the surface temperature becomes colder, there will be a vertical flow from the bottom of the water to the surface because of the difference of the density of water. The movement of water in the bottom of the water to surface waters would bring the basic material. Material that mostly contains NH3 will cause the DO level to drop drastically. The condition is known as upwelling.

With continuous monitoring, fish farmers can determine, when some conditions allow the upwelling may perform the anticipation

\section{CONCLUSION}

Based on the functionality testing on the experimental environment, upwelling monitoring system uses temperature sensors and DO sensors can do detection, storage, and monitoring of temperature and DO levels properly. After testing the functionality, the monitoring system implemented on Cirata, with two scenarios. Tests are on karamba areas and on non-karamba area. The test results showed the karamba regions have higher water temperatures, while lower levels of DO. The difference in temperature between the karamba area and the non karamba area are around $0.22^{\circ} \mathrm{C}$ on the bottom of the water, and $0.88^{\circ} \mathrm{C}$ on the surface of the water. Average DO levels in the karamba area are lower 1:57 mg/L compared to non-karamba area. From this result, fish farmers can monitor the condition of karamba every day, to determine response detection responsethat allows upwelling condition. The next development, the monitoring system will be installed with fuzzy algorithm to predict the chances of upwelling.

\section{ACKNOWLEDGMENT}

The Authors thank the Higher Education Directorate of National Education Ministry of Indonesia (DIKTI) for funding support in this research through "Hibah Bersaing" scheme. This research is fully funded by Higher Education Directorate of Education and Cultural Ministry of Indonesia (DIKTI). We would also like to thank Telkom University for administration and infrastructure support. Specifically, we would like to thank the HES team (Chadyan, Andra, Fajar, Rizki, Dika, Musa, and Satrio) who helped us implement the system. 
Novian A Suwastika Et.al.

\section{REFERENCES}

Bakker, D. C., Etcheto, J., Boutin, J., \& Merlivat, L. (2001). Variability of surface water fCO2 during seasonal upwelling in the equatorial Atlantic Ocean as observed by a drifting buoy. Journal of Geophysical Research: Oceans (1978-2012), 106(C5), 9241-9253

Bondarenko, O., Kininmonth, S., \& Kingsford, M. (2007, December). Underwater sensor networks, oceanography and plankton assemblages. In Intelligent Sensors, Sensor Networks and Information, 2007. ISSNIP 2007. 3rd International Conference on (pp. 657662). IEEE

Bondarenko, O., Kininmonth, S., \& Kingsford, M. (2007, October). Coral reef sensor network deployment for collecting real time 3-D temperature data with correlation to plankton assemblages. In Sensor Technologies and Applications, 2007. SensorComm 2007. International Conference on (pp. 204-209). IEEE

El-Basioni, B. M. M., El-kader, S. M. A., \& Abdelmonim, M. (2013). Smart home design using wireless sensor network and biometric technologies. Information technology, 1, 2

Fink, J. C. (2005, August). CHAPTER 4 - ESTABLISHING A RELATIONSHIP BETWEEN SEDIMENT CONCENTRATIONS AND TURBIDITY. In The Effects of Urbanization on Baird Creek, Green Bay, WI (Thesis). Retrieved from http://www.uwgb.edu/watershed/fink/Fink_Thesis_Chap4.pdf

Fondriest Environmental, Inc. (2014, November) “Dissolved Oxygen.” Fundamentals of Environmental Measurements. Web. $<$ http://www.fondriest.com/environmental-measurements/parameters/water-quality/dissolved-oxygen/ >.

Gao, Q. (2006, November). Correlation of Total Suspended Solids (TSS) and Suspended Sediment Concentration (SSC) Test Methods. In New Jersey Department of Environmental Protection Division of Science, Research, and Technology. Retrieved from http://www.state.nj.us/dep/dsr/soils/tss $\% 20 \mathrm{vs} \% 20$ ssc $\% 20$ test $\% 20$ methods.pdf

Langland, M., \& Cronin, T. (Eds.). (2003). A Summary Report of Sediment Processes in Chesapeake Bay and Watershed. In WaterResources Investigations Report 03-4123. New Cumberland, PA: U S Geological Survey. Retrieved from http://pa.water.usgs.gov/reports/wrir03-4123.pdf

Milenković, A., Otto, C., \& Jovanov, E. (2006). Wireless sensor networks for personal health monitoring: Issues and an implementation. Computer communications, 29(13), 2521-2533

Pollin, S., Ergen, M., Ergen, S., Bougard, B., Der Perre, L., Moerman, I., \& Catthoor, F. (2008). Performance analysis of slotted carrier sense IEEE 802.15. 4 medium access layer. Wireless Communications, IEEE Transactions on, 7(9), 3359-3371.)

Pompili, D., Melodia, T., \& Akyildiz, I. F. (2006, September). Deployment analysis in underwater acoustic wireless sensor networks. In Proceedings of the 1st ACM international workshop on Underwater networks (pp. 48-55). ACM

Puebla, O. (2009). Ecological speciation in marine v. freshwater fishes. Journal of Fish Biology, 75(5), 960-996

Quibell, G. (1992). Estimating chlorophyll concentrations using upwelling radiance from different freshwater algal genera. International Journal of Remote Sensing, 13(14), 2611-2621.

Send, U., \& Nam, S. (2012). Relaxation from upwelling: the effect on dissolved oxygen on the continental shelf. Journal of Geophysical Research: Oceans, 117(C4).

Shaw, P. T., Chao, S. Y., Liu, K. K., Pai, S. C., \& Liu, C. T. (1996). Winter upwelling off Luzon in the northeastern South China Sea. Journal of Geophysical Research: Oceans (1978-2012), 101(C7), 16435-16448.

Shaw, P. T., Chao, S. Y., Liu, K. K., Pai, S. C., \& Liu, C. T. (1996). Winter upwelling off Luzon in the northeastern South China Sea Journal of Geophysical Research: Oceans, 101(C7), 16435-16448.

Tseng, Y. F., Lin, J., Dai, M., \& Kao, S. J. (2014). Joint effect of freshwater plume and coastal upwelling on phytoplankton growth off the Changjiang River. Biogeosciences, 11(2), 409-423.

Umar, Chairul (2010) Kajian Kualitas Air Untuk Mendukung Perikanan Di Waduk Cirata. Web < http://www.sidik.litbang.kkp.go.id/index.php/searchkatalog/byId/9441>

Weeks, S. J., Pitcher, G. C., \& Bernard, S. (2004). Satellite monitoring of the evolution of a coccolithophorid bloom in the southern Benguela upwelling system. Oceanography, 17(1), 83-89

Wetzel, R. G. (2001). Limnology: Lake and River Ecosystems (3rd ed.). San Diego, CA: Academic Press.] [Langland, M., \& Cronin, T. (Eds.). (2003). A Summary Report of Sediment Processes in Chesapeake Bay and Watershed. In Water-Resources Investigations Report 03-4123. New Cumberland, PA: U S Geological Survey. Retrieved from http://pa.water.usgs.gov/reports/wrir03-4123.pdf 
Yu, L., Wang, N., \& Meng, X. (2005, September). Real-time forest fire detection with wireless sensor networks. In Wireless Communications, Networking and Mobile Computing, 2005. Proceedings. 2005 International Conference on (Vol. 2, pp. 1214-1217). IEEE 
